\title{
Nebria (Pseudonebriola) tsambagarav sp. nov., a new alpine species from the Mongolian Altai (Coleoptera, Carabidae)
}

\author{
Charles Huber ${ }^{1}$, Peer Hajo Schnitter ${ }^{2}$ \\ 1 Natural History Museum, Bernastrasse 15, CH-3005 Bern, Switzerland \\ 2 Gartenstadtstraße 8, D-06126 Halle (Saale), Germany \\ http://zoobank.org/7C1EAAF3-2DD3-4307-ABA1-D9AAD6F795F2 \\ Corresponding author: Charles Huber (charles.huber@nmbe.ch)
}

Academic editor: C. Germann • Received 23 January 2020 • Accepted 12 February 2020 • Published 15 April 2020

\begin{abstract}
Nebria (Pseudonebriola) tsambagarav sp. nov. is described from an alpine altitude in the Mongolian Altai. The new species is separated from other two Pseudonebriola species from the Mongolian Altai Mountain range, N. kerzhneri and N. medvedevi, by morphometric and morphological analyses. The new species and its habitat are illustrated, the subgeneric key is amended, and a distribution map is given.
\end{abstract}

\section{Key Words}

carabids, morphometry, multivariate ratio analysis, taxonomy, distribution, high altitude

\section{Introduction}

The subgenus Pseudonebriola Ledoux \& Roux, 1989, genus Nebria Latreille, 1802 comprises 13 species and two subspecies (Huber 2017), distributed over the mountain ranges of Central Asia in Kazakhstan, Kirgizia, China, Mongolia, and Russia. The distribution area of Pseudonebriola extends from the Yssyk Kul in Kirgizia to the Baikal Lake in South Eastern Russia. Only the recently described $N$. (P.) mingyii Ledoux \& Roux, 2014 from the Qilian Shan, Qinghai, China, stands isolated from the distribution area of the other species known so far (Ledoux and Roux 2014). Species of the subgenus Pseudonebriola generally inhabit alpine altitudes between 2000 and $3500 \mathrm{~m}$ a.s.l.

Up to now four Pseudonebriola species are known from the Altai Mountains, a border mountain range common to Kazakhstan, Russia, China, and Mongolia: $N$. kaszabi Shilenkov, 1982 from the Kazakhstan and Russian part, N. stanislavi Dudko \& Matalin, 2002, an endemic species in the Russian Altai, N. medvedevi Shilenkov, 1982 from the Mongolian (and Russian) Altai, and N. kerzhneri Shilenkov, 1982, endemic to the Gobi Altai, the Southeastern continuation of the Mongolian Altai
(Shilenkov 1982a, b; Dudko and Matalin 2002; Ledoux and Roux 2005; Huber 2017).

Pseudonebriola specimens were collected by the junior author on the occasion of an expedition in 2016 to the Tsambagarav uul, Mongolian Altai, Northwestern Mongolia. The Tsambagarav Mountain is part of the central Mongolian Altai bordering the Great Lakes Depression and is separated from the main ridges of the Mongolian Altai by a straight tectonogenic hollow (Borodavko et al. 2018). The collected specimens do not agree either morphologically or morphometrically with any of the known species. Hence they are described below as a new species of the subgenus Pseudonebriola.

\section{Materials and methods}

The edeagi and gonocoxae were dissected and dehydrated in alcohol and xylene, and finally embedded in Fluka DPX Mountant on transparent mounting cards.

For a morphometric analysis we measured eleven characters (Table 1) of 31 specimens of four Pseudonebriola taxonomic units from the Altai Mountain range: 
Table 1. Characters measured in the Nebria kerzhneri species complex for use in a morphometric analysis.

\begin{tabular}{|c|c|c|c|}
\hline Abbreviation & Character & Definition & Conversion factor \\
\hline eye.I & eye length & length of eye & 0.074 \\
\hline ant.w & antennomere 1 width & maximum width of antennomere 1 & 0.074 \\
\hline ant.l & antennomere 1 length & length of antennomere 1 & 0.074 \\
\hline ely.w & elytra width & maximum width of elytra & 0.01 \\
\hline ely.I & elytron length & $\begin{array}{c}\text { length of elytron from basal margin } \\
\text { to apex }\end{array}$ & 0.01 \\
\hline fro.w & frons width & width of frons between the eyes & 0.026 \\
\hline hea.w & head width & maximum width of the head (over eyes) & 0.026 \\
\hline pra.w & pronotum anterior width & $\begin{array}{c}\text { width between the anterior angles of } \\
\text { the pronotum }\end{array}$ & 0.026 \\
\hline prm.w & pronotum maximum width & maximum width of the pronotum & 0.026 \\
\hline prm.l & pronotum median length & median length of the pronotum & 0.026 \\
\hline prp.w & pronotum posterior width & $\begin{array}{l}\text { width between the posterior angles of } \\
\text { the pronotum }\end{array}$ & 0.026 \\
\hline
\end{tabular}

N. kaszabi (eigth specimens) which belongs to the sajanica species group (sensu Ledoux and Roux 2005), $N$. medvedevi (two type specimens) and N. kerzhneri (holotype specimen), both of the kerzhneri species group, and a sample of 20 specimens of the type series of the new species from Mt Tsambagarav, Mongolia. The measurements were taken using a Leica MZ 16 stereo-microscope with an ocular micrometer. Measurements of males and females were pooled, since their values were entirely overlapping in range. We applied multivariate ratio analysis (MRA) of Baur and Leuenberger (2011) to our data of a complex of four operational taxonomic units (OTU), the kerzhneri, medvedevi, kaszabi and tsambagarav units. For information on the application of the principal component analysis of shape (shape PCA) and the linear discriminant analysis (LDA) ratio extractor, we refer to the studies on the species complexes of Nebria (Patrobonebria) paropamisos Huber, Schmidt \& Baur, 2013 (Huber et al. 2013), of N. (P.) desgodinsi Oberthür, 1883 (Huber and Baur 2016), of N. (Eunebria) xanthacra Chaudoir, 1850 (Huber and Schmidt 2018), and of Encarsia pergandiella Howard, 1907 (Hymenoptera, Aphelinidae; Gebiola et al. 2017). Morphometric analyses were done using the R statistical environment (R Core Team 2013).

The photographs were taken with a digital camera Leica MC 190 HD using a motorised focusing drive. The pictures are composites processed using the Leica Application Suite X (LAS X) 3.6.0.20104 software, and were retouched using Adobe Photoshop version 10.0.1. The median lobes of the type specimens of both $N$. kerzhneri and $N$. medvedevi were originally glue-fixed on mounting cards. The photographs of the median lobes were taken in that dried situation. The habitus photograph was taken by a digital microscope Keyence VHX-2000 with the objective VH-Z20R.

The distribution map (Fig. 11) was drawn using the QGIS Version 3.8 Zanzibar Software. Additional localities were taken from Shilenkov (1982b; N. medvedevi, N. kerzhneri) and from Dudko and Matalin (2002; N. kaszabi (selection), N. stanislavi, N. medvedevi). In case of non-georeferenced localities we used approximate geo- graphic coordinates of online systems (Google Earth, Google Maps), which are given in square brackets.

Collections examined with acronyms:

NMBE Natural History Museum Bern, Switzerland.

ZIN Zoological Institute of the Russian Academy of Sciences, St Petersburg, Russia.

cBK private collection of I.A. Belousov and I.I. Kabak, St Petersburg, Russia.

cSCHN collection Peer Schnitter, Halle, Germany.

For abbreviations of morphological characters see Tab. 1.

Type material examined [with authors' remarks or supplements in square brackets]:

N. medvedevi: Holotype $\widehat{\partial}$ and 1 paratype $\widehat{\partial}$ : [red label] Holotype [and Paratype respectively; printed, in Latin letters], Nebria medvedevi sp. nov. Shilenkov det. 1981 [handwritten, in Latin letters] // [white label] 7. 7. 1980; MNR Kobdosk. aim. Mongolsk. Altai, per. Ulan-Daba [47²3.96’ N; 91⒓23'E], G. Medvedev [handwritten, in Cyrillic letters] // 3000-3200 m, под камнями у снежниов [handwritten, in Cyrillic letters] (ZIN). Original description of the type locality by Shilenkov (1982b, p. 254): Mongolia, border of Kobdoskii and Bayan-Ulzgzai aimaks, Mongolian Altai, per. Ulan-Daba, 3000-3200 m, leg. G. Medvedev.

N. kerzhneri: Holotype $\hat{\sigma}$ [red label]: Holotypus [printed, in Latin letters], Nebria kerzhneri sp. nov. Shilenkov det. 1980 [handwritten, in Latin letters] // [white label] 28. 6. 1973, Gobi-Altai Aimak, Dschargalan [4658.59’ N; 9555.07’'E], в старых ходах рогохвоста [handwritten, in Cyrillic letters]. V. Yanovskiy [printed, in Cyrillic letters] (ZIN).

Additional material examined:

N. kaszabi: 2 † Vostochno-Kasachst., Marka-Kul, above Urunkhaika, 2400 m, 25. 6. 1986, leg. Shilenkov [in Cyrillic letters] // Nebria kaszabi Shil., det Shilenkov 1994 (NMBE). 3 ก , 3 q RUS SW-Altai, Markakol Lake/ Urunkhaika, $2400 \mathrm{~m}\left[48^{\circ} 45.90^{\prime} \mathrm{N} ; 8^{\circ} 09.62^{\prime} \mathrm{E}\right], 19.6$. 1997, leg. Dudko, det. Dudko (NMBE). 
Additional localities of non-examined specimens used for the distribution map (Fig. 11):

N. medvedevi: In June 1998 A. Matalin and D. Fedorenko collected $N$. medvedevi specimens for the first time in a Russian area: Ukok Highland, Teplyy Klyuch, $2640 \mathrm{~m}\left[49^{\circ} 07.703^{\prime} \mathrm{N} ; 8^{\circ} 26.605^{\prime} \mathrm{E}\right]$.

N. kerzhneri: Paratypes: Hasagt-Khairkhan, $15 \mathrm{~km}$ South of Jargalan, 14.8.1970, leg. Kerzhner [ $46^{\circ} 47.42^{\prime} \mathrm{N}$; $\left.95^{\circ} 48.23^{\prime} \mathrm{E}\right]$. Taishirin-Ula, $15 \mathrm{~km}$ Southeastern of Altai [Altai $=$ village in the Northwestern part of the Gobi Altai: 46² $12.96^{\prime} \mathrm{N}$; $\left.96^{\circ} 27.66^{\prime} \mathrm{E}\right], 20.8 .1970$, leg. Emelyanov (Shilenkov 1982b).

N. stanislavi: Central Altai, Eastern slope of Mt. Kyzylart [50 $\left.32.20^{\prime} \mathrm{N} ; 87^{\circ} 12.28^{\prime} \mathrm{E}\right]$, spring of river Achin, 2100-2300 m (Dudko and Matalin 2002).

\section{Results}

\section{Morphometry}

The scatterplots of the first scape PC against isosize of the four OTUs do not overlap and show no sign of allometry (Fig. 1). The kerzhneri red dot, which seems to be close to the tsambagarav scatterplot, lies in a double distance far from the regression line as the furthermost tsambagarav outlier. We consider all units as distinctly separated.

The LDA ratio extractor provides the best ratios to separate the groups. The best two ratios to discriminate the tsambagarav unit from the sample of the two kerzhneri and medvedevi units (ker+med in Fig. 2A) from the Mongolian Altai are the antennal scape length/eye length on the one hand and the elytral width/median pronotum

A

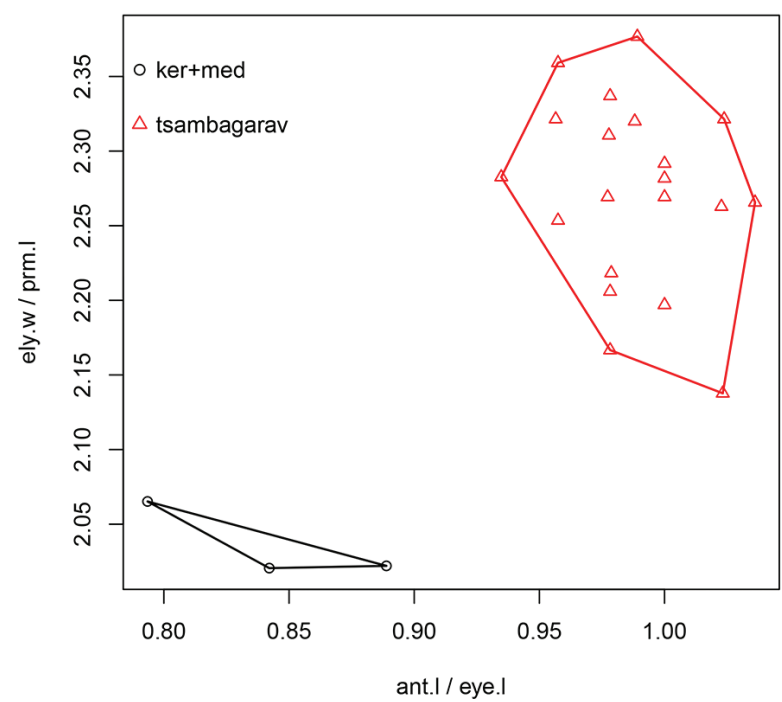

length on the other (Fig. 2A). We use the former in the determination key below, the second-best ratio is unusual in taxonomy.

Furthermore, we examined eight specimens of $N$. (P.) kaszabi, a member of the sajanica species group, as a geographical and taxonomic outgroup. The LDA extractor provides the same ratio (the antennal scape length/ eye length) as best ratio to separate the tsambagarav and kaszabi units, supported by the second best ratio of elytral length/head width (Fig. 2B).

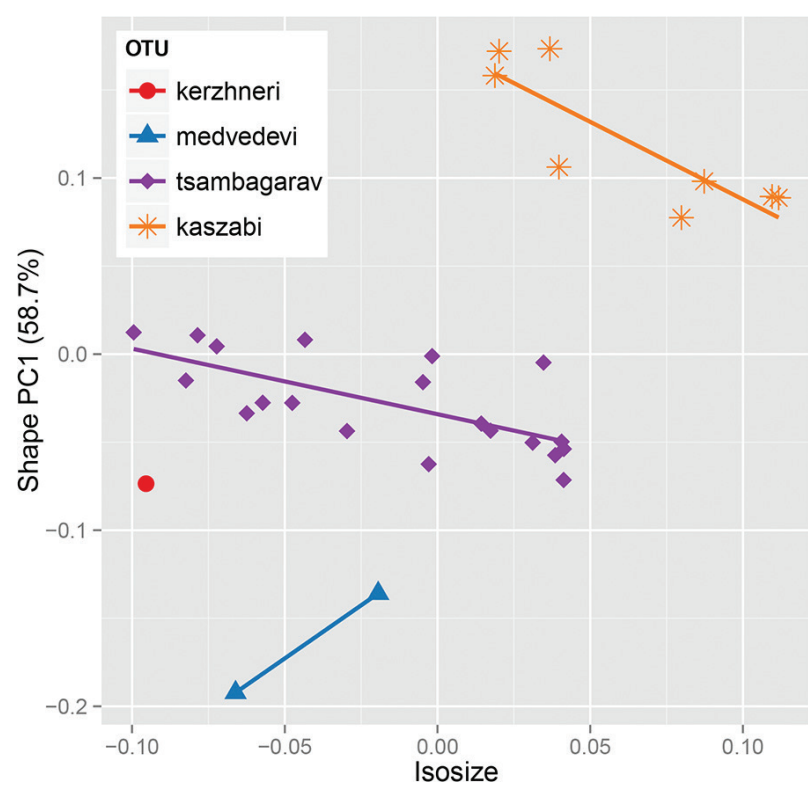

Figure 1. Multivariate ratio analysis. Scatterplot of isosize against first shape PC of four Altai Pseudonebriola OTUs, including all eleven examined variables. OTU $=$ operational taxonomic units.

B

First and second best ratio

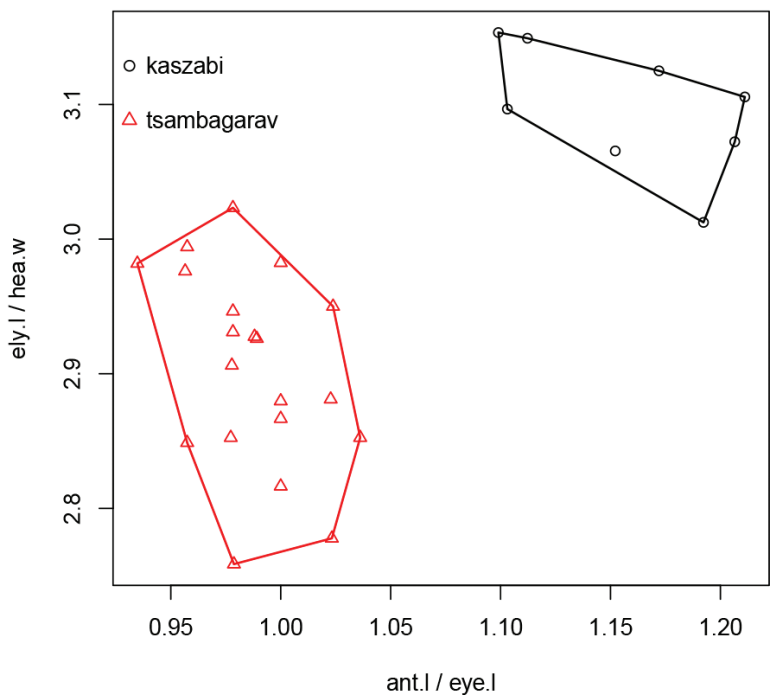

Figure 2. Best and second-best diagnostic ratios by linear discriminant analysis (LDA) ratio extractor for separating groups: A, in Nebria (Pseudonebriola) tsambagarav sp. nov. and the two other species of the Mongolian Altai N. (P.) medvedevi Shilenkov, 1982 and $N$. (P.) kerzhneri Shilenkov, 1982 (= ker+med); B, in N. (P.) tsambagarav sp. nov. as a member of the kerzhneri species group and $N$. (P.) kaszabi Shilenkov, 1982 as a member of the sajanica species group of the Kazakhstan and Russian Altai. 


\section{Taxonomy}

\section{Nebria (Pseudonebriola) tsambagarav sp. nov.}

http://zoobank.org/49BA78BD-7423-410B-A311-9BD18A1C134D

Figs 3-8

Type material. Holotype ${ }^{\prime}: 48^{\circ} 41^{\prime} 27.1^{\prime \prime} \mathrm{N}, 90^{\circ} 40^{\prime} 33.4$ 'E; Mongolei, Bajan Ulgij Aimak, Tsambagarav uul; alpine Zone: Bachufer; 3168 üNN; 1. 7. 2016; 20 MG 2016 [internal abbreviation of the collector: location No. 20, Mongolia expedition 2016]; leg. Schnitter (NMBE).

Paratypes: $31 \hat{\sigma}, 22+$, same data as holotype (NMBE, ZIN, cBK, cSCHN).

Description. Body size: $7.5-9 \mathrm{~mm}$.

Colour: Dorsal surface black, head black, without lightened spots on the vertex; appendages of the head brownish lightened, always lighter than the head. Antennal scape black, antennomeres 2-11 brown with darkened apices. Femora black, tibiae and tarsomeres brown, apices of tarsomeres usually black.

Head: Mandibles short; stipes flat, smooth, with 4-6 setae. Anterior margin of the labrum straight, bearing six setae. Anterior margin of the clypeus straight or slightly concave; clypeus laterally unisetose. Frontoclypeal

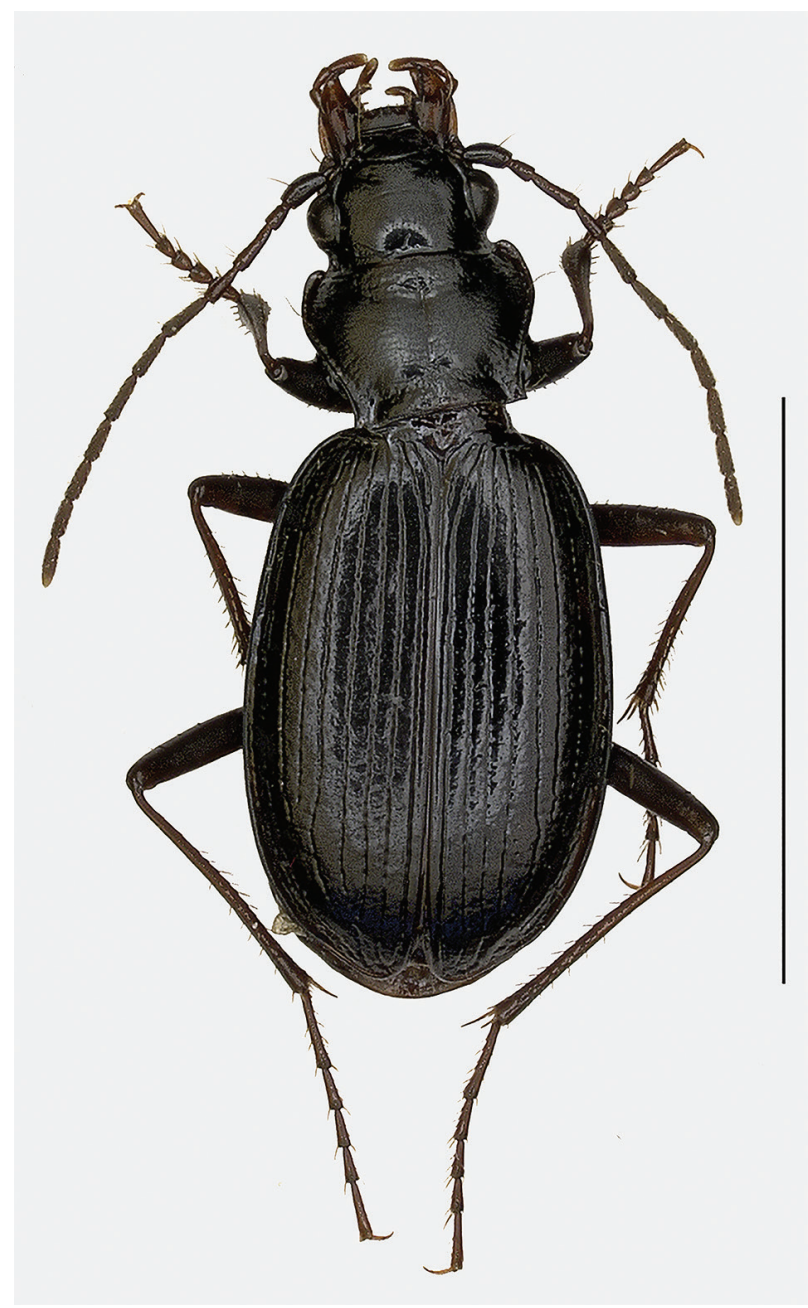

Figure 3. Nebria (Pseudonebriola) tsambagarav sp. nov., habitus, holotype. Scale bar: $5 \mathrm{~mm}$. suture concave. Frons with transverse wrinkles, which roundly merge into the lateral and longitudinal supraorbital wrinkles. Eyes protruding, temples present, oblique. Head supraorbitally unisetose. Disc impunctate with an isodiametric microreticulation. Antennae long and thin, extending to the end of the basal third of the elytra. Antennal scape as long as the eye's diameter (ratio antennal scape length/eye length $=0.98 \pm 0.03(0.93-1.04)$, slightly conical to suboval, distinctly narrowed basally and slightly apically, with one dorsoapical seta (Fig. 4). Ratio antennal scape length/scape width $=2.16 \pm 0.07(2.05-2.26)$. $2^{\text {nd }}$ antennomere with one long ventroapical and one long dorsoapical seta, and generally (in $89 \%$ of the examined specimens) with 1-2 additional, often hardly visible short setae on the apex; therefore the $2^{\text {nd }}$ antennomere trisetose (in $47 \%$ ) or even quadrisetose (in $42 \%$ ) (Fig. 5). Ligula short, triangular, broad at base, with two apical setae. Penultimate labial palpomere trisetose. Mentum bidentate, medially hardly incised. Median teeth with one seta
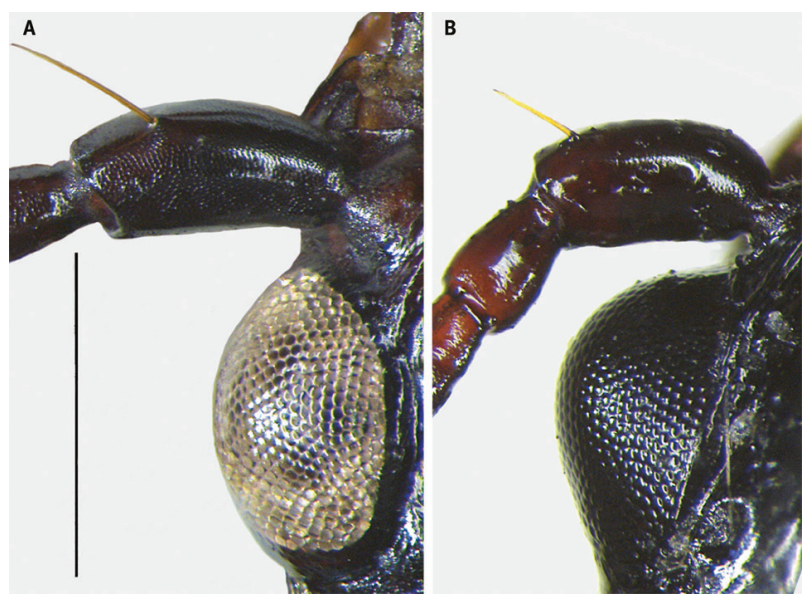

Figure 4. Antennal scape: A, Nebria (Pseudonebriola) tsambagarav sp. nov. paratype; B, N. (P.) medvedevi Shilenkov, 1982, paratype. Scale bar: $0.5 \mathrm{~mm}$.

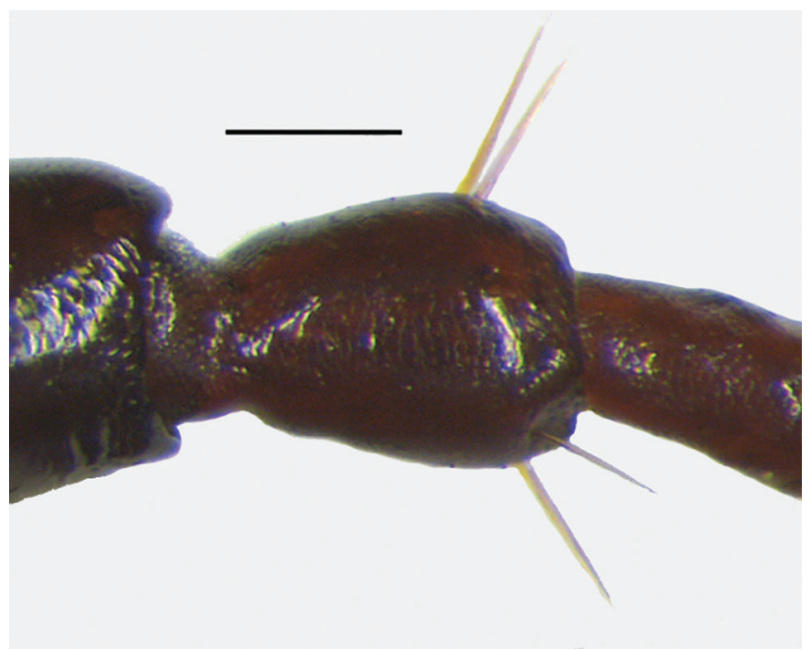

Figure 5. Second antennomere of right antenna of Nebria (Pseudonebriola) tsambagarav sp. nov., paratype, with four apical setae. Scale bar: $0.1 \mathrm{~mm}$. 
at each side. Lobus lateralis of the mentum wide, apically faintly rounded or even rectilinearly narrowed, spina apicalis short, triangular, incisio lateralis distinct. Submentum bilaterally with 3-4 setae.

Pronotum (Fig. 6): Cordate, widest at apical third or even forth; ratio maximum width/length $=1.43 \pm 0.03$ (1.39-1.49). Anterior angles widely rounded, faintly protruding. Lateral margin evenly rounded to the anterior angles, faintly rounded to the posterior angles with a distinct sinuation in front of the posterior angle. Lateral margin of the posterior angles long. Posterior angles rectangular or even acutely turned outwards. Ratio apical pronotal width/maximum pronotal width $=0.80 \pm 0.02(0.78-0.84)$. Apical margination of the pronotum restricted to lateral one-third. Basal margin straight, occasionally laterally faintly curved, the posterior angles not protruding backwards. Basal width of the pronotum 0.92 (0.88-0.97) times the anterior width. Lateral groove distinct, narrow, flat, impunctate or with isolated dents, laterally narrowly edged, slightly broadened to the anterior angle, posteriorly joining the deep basal fovea. One midlateral seta present near widest point of the pronotum; occasionally bilateral-bisetose $(2 \%)$ or asymmetrically uni-/bisetose $(2 \%)$. Basolateral seta present. Apical and basal transverse impression coarsely but sparsely punctate. Median longitudinal impression distinct, reaching the posterior border of the pronotum. Disc with isodiametric microreticulation. Prosternal process wide, triangular, laterally slightly margined, medially flat, apically bulging and immarginate. Proepisternum smooth and impunctate.

Elytra: Silhouette suboval, apically faintly expanded, maximum width at two thirds. Ratio length/width of the elytra $=1.53 \pm 0.02(1.51-1.57)$. Elytral width $=$ $1.59 \pm 0.04(1.51-1.66)$ times the pronotal width. Lateral margin faintly rounded, apex acutely rounded. Basal mar- gination slightly curved, joined at an obtuse angle with the lateral margination. Shoulder flatly curved. Hindwings vestigial. Humeral and apical carinae little pronounced. Striae 1-7 distinct, punctate, stria 8 as a row of punctures. Striae 1-3 reaching the apex, the other striae obliterate slightly in front of the apex. Intervals on disc flat, interval 3 generally asetose $(76 \%)$ on disc, disregarding the always present apical seta, occasionally with one seta on the disc (24\%). Scutellar seta absent. Microsculpture isodiametric.

Ventral surface: Mes- and Metepisterna smooth and impunctate. Metacoxa basally and apically unisetose. Sternum II laterally faintly and widely dispersed punctate. Sternum III medially asetose. Sterna IV-VI each with one posterior paramedial seta. Anal sternum paralaterally unisetose in the male, bisetose in the female.

Legs: All tarsomeres dorsally glabrous; metatarsomere 4 ventrally with a short projecting tooth. Metafemur dorsoapically with a few short setae.

Male genitalia: Edeagus (Fig. 7C): Base of the median lobe small; the base decreasing abruptly to the thin midshaft. Mid-shaft strongly curved at base on inner side, moderately curved to the apex. Apex straight, faintly deflected to the left, in front of the long tip ventrally faintly convex. Mid-shaft of the endophallus with short setae.

Female genitalia: Gonocoxa (Fig. 8A): Gonocoxite 2 slender, dagger-like, curved, two fifth the length of gonocoxite 1 , broad at base, distinctly narrowing near base, narrowing towards apex which is faintly deflected. Apex rounded, hardly arcuate and grooved dorsally. Ventral preapical insertion furrow short-oval, with two nematiform setae. Gonocoxites ventrally unjointed and continuously sclerotized, dorsally separated by a membranous area.

Habitat (Figs 9, 10). The new species was found in the alpine region of the Tsambagarav uul exclusively un-
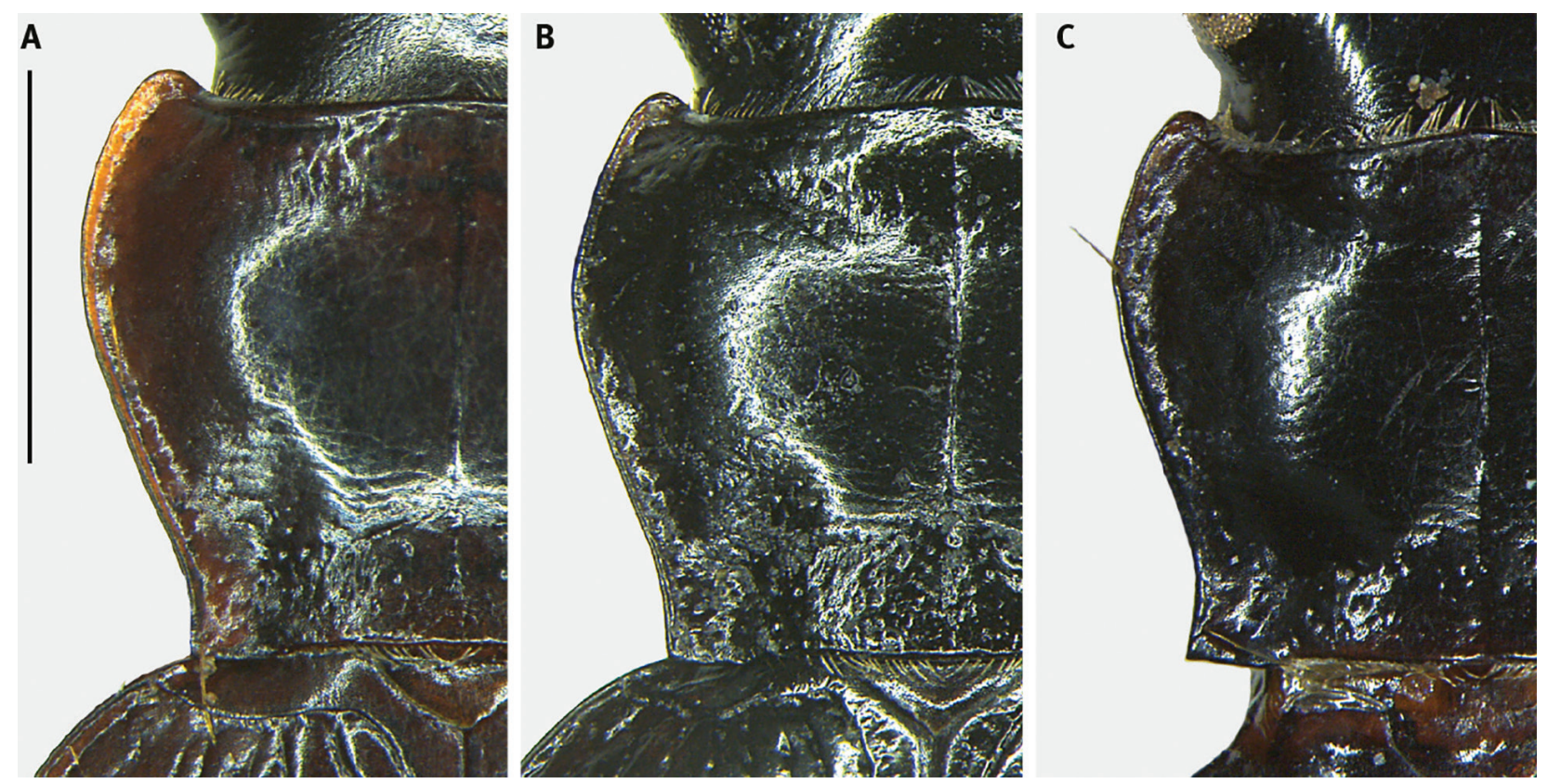

Figure 6. Pronotum: A, Nebria (Pseudonebriola) kerzhneri Shilenkov, 1982, holotype; B, N. (P.) medvedevi Shilenkov, 1982, paratype; C, N. (P.) tsambagarav sp. nov., paratype. Scale bar: $1 \mathrm{~mm}$. 


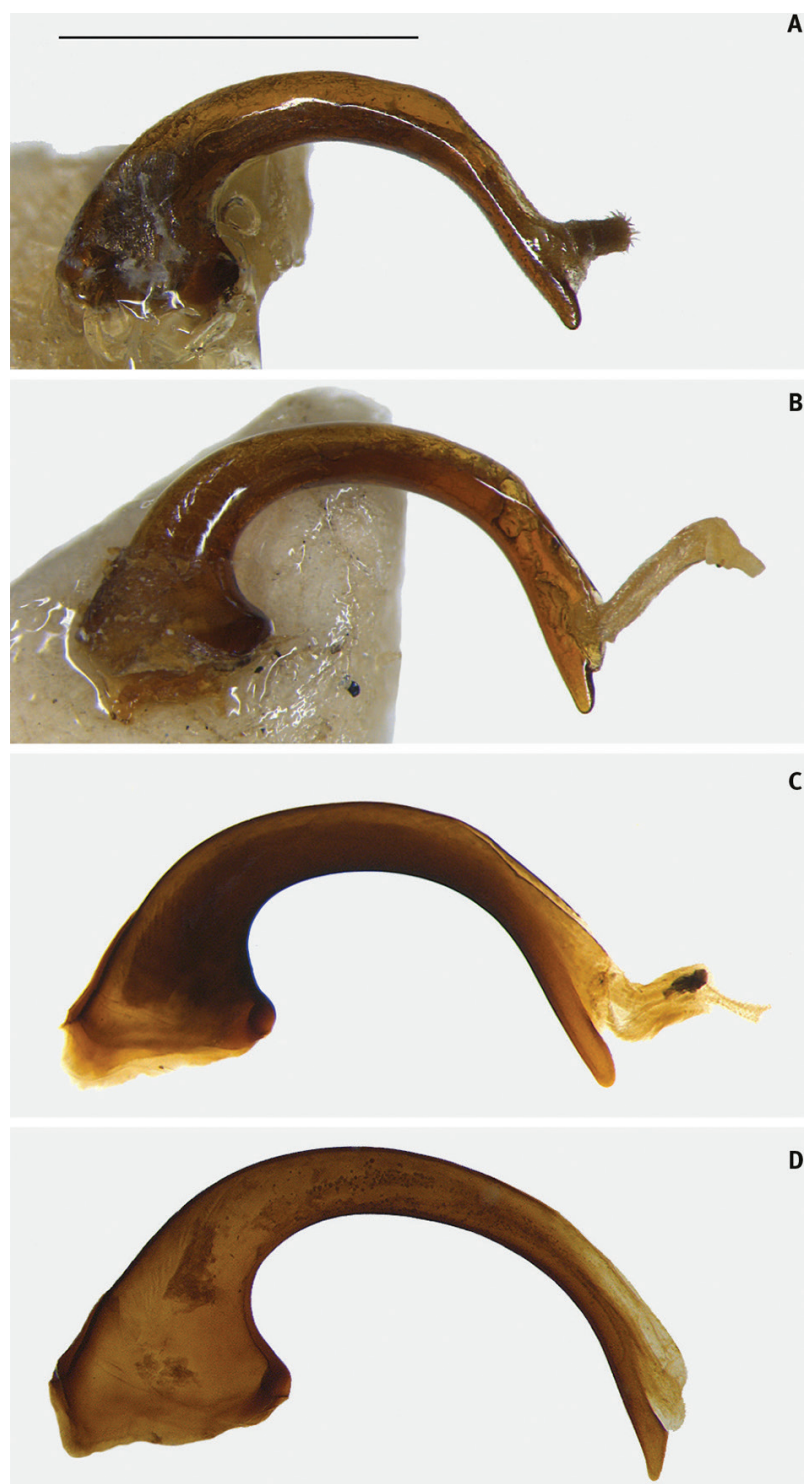

Figure 7. Median lobes; A-B dried lobes, C-D embedded lobes, A-C with partially everted endophallus: A, Nebria (Pseudonebriola) kerzhneri Shilenkov, 1982, holotype; B, N. (P.) medvedevi Shilenkov, 1982, paratype; C, $N$. (P.) tsambagarav sp. nov., holotype; D, N. (P.) kaszabi Shilenkov, 1982, Urunkhaika, Marakol Lake, Kazakhstan. Scale bar: $1 \mathrm{~mm}$.

der bigger stones along the riverbanks of small rivulets. The water ran off higher snowfields. Directly at the snow fields not any specimen was found.

Ecology. Hydrophilic, ripicol, cold-preferring, alpine level.

Etymology. The specific epithet refers to the type locality, the Tsambagarav uul; noun in apposition.

Distribution (Fig. 11). N. tsambagarav sp. nov. is known only from the type locality at an altitude of 3168 $\mathrm{m}$ a.s.l. at the Tsambagarav uul, a mountain (with the summit at $4165 \mathrm{~m}$ a.s.1.) of the Mongolian Altai in the westernmost province of Bayan Ölgii of Mongolia.

The Mongolian Pseudonebriola species are restricted to the main ridge of the Mongolian Altai (N. medvedevi), to the Tsambagarav mountain, the easternmost
A

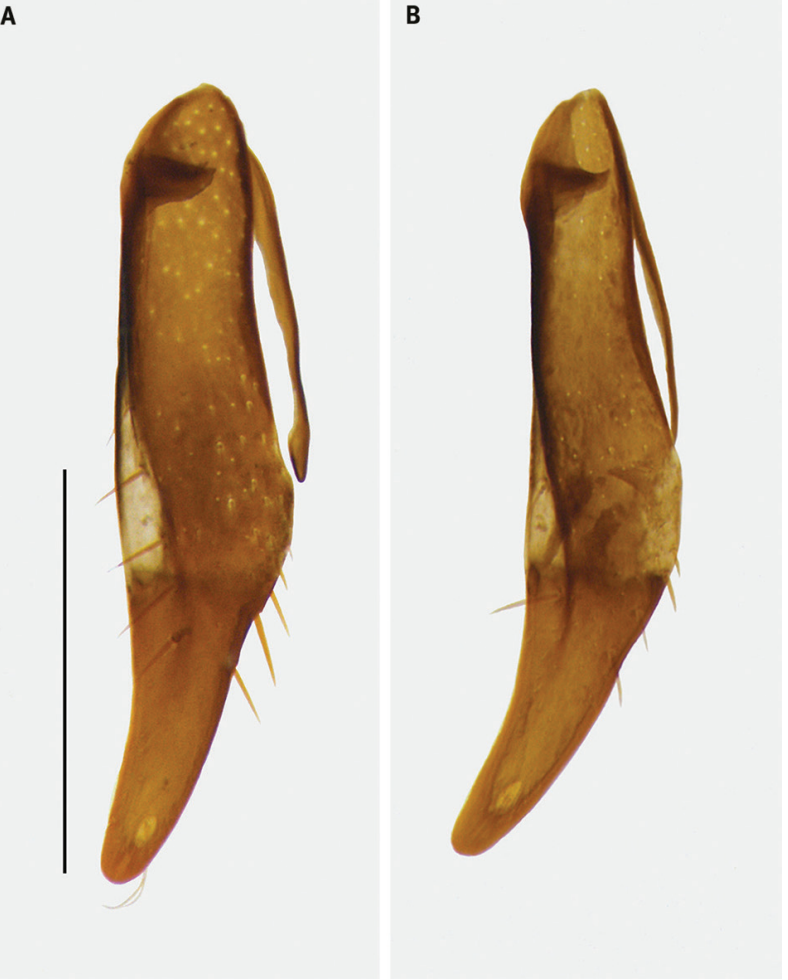

Figure 8. Right gonocoxa (in ventral view): A, Nebria (Pseudonebriola) tsambagarav sp. nov., paratype; B, $N$. (P.) kaszabi Shilenkov, 1982; Urunkhaika, Marakol Lake KAZ. Scale bar: $0.5 \mathrm{~mm}$.

ridge bordering the Great Lakes Depression (N. tsambagarav sp. nov.), and to the Northwestern part of the Gobi Altai (N. kerzhneri).

\section{Differential diagnoses to Pseudonebriola species of the Mongolian Altai}

Antennae: Antennal scape (in relation to the eye length) in $N$. tsambagarav sp. nov. longer than in N. kerzhneri and in $N$. medvedevi, the ratio scape length/eye length distinctly different: 0.98 in $N$. tsambagarav sp. nov., 0.89 in N. kerzhneri, and 0.82 in $N$. medvedevi (see also fig. 2 in Dudko and Matalin (2002), p. 1079).

Second antennomere of $N$. tsambagarav sp. nov. oligosetose with (2)3-4 setae (Fig. 5). The examined specimens are oligosetose on the $2^{\text {nd }}$ antennomere in $89 \%$ of the cases, and bisetose in $11 \%$. This seta character of the $2^{\text {nd }}$ antennomere was not mentioned by Shilenkov (1982b), when he described N. kerzhneri, but explicitly mentioned as bisetose (and sometimes unisetose) in $N$. medvedevi. Shilenov (1982b) pictured this seta character in a drawing (fig. 19, p. 251) with an unisetose $2^{\text {nd }}$ antennomere in $N$. kerzhneri in contrast to a bisetose one in N. medvedevi (fig. 20, p. 251). Ledoux and Roux (2005) did not mention this character either in $N$. kerzhneri or in $N$. medvedevi.

Pronotum: In N. tsambagarav sp. nov. the lateral groove of the pronotum at the anterior angle is wider than 




Figure 9. Tsambagarav uul, Bajan Ölgii province, Western Mongolia. Photo: Peer Schnitter.

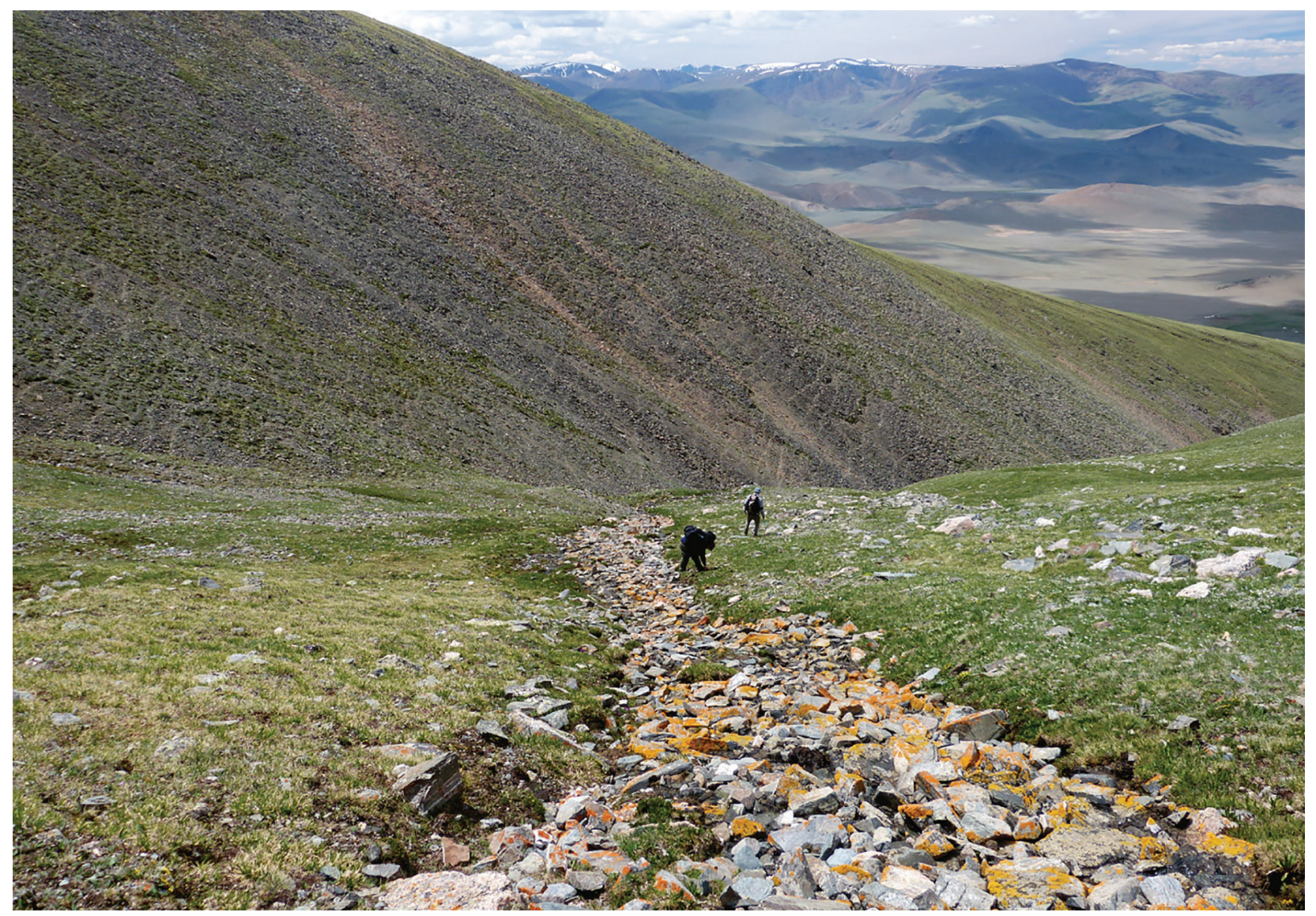

Figure 10. Habitat of Nebria (Pseudonebriola) tsambagarav sp. nov. on Tsambagarav uul; rivulet at $3168 \mathrm{~m}$ a.s.1. Photo: Peer Schnitter. 




Figure 11. Map of the Altai Mountain range displaying the distribution of Pseudonebriola species.

in N. kerzhneri and N. medvedevi. Lateral margin of the pronotum at the anterior angle distinctly edged as in $N$. medvedevi; such an edged anterolateral margin is absent in $N$. kerzhneri. In $N$. tsambagarav sp. nov. the pronotum is distinctly concave in front of the posterior angles (Fig. 6C), therefore the posterior angle is acute and prominently turned outwards in contrast to the rectangular angle in $N$. kerzhneri and $N$. medvedevi respectively, in the latter the pronotal margin in front of the posterior angle is only faintly concave (Fig. 6B).

Edeagus: The tip of the edeagus in N. tsambagarav sp. nov. is longer (Fig. 7C) in contrast to those in N. kerzhneri and N. medvedevi (Fig. 7A, B). Whereas the apex in $N$. tsambagarav sp. nov. is straight and ventrally faintly convex as in both $N$. kerzhneri and $N$. medvedevi, the shortly pointed apex of the edeagus of $N$. kaszabi is regularly bent without any ventral convexity (Fig. 7D), an indication that N. kaszabi (from Kazakhstan and Russian Altai) may belong to another species group.

Gonocoxa: Gonocoxite 1 of $N$. tsambagarav sp. nov. (Fig. 8A) wider and gonocoxite 2 less curved than in $N$. kaszabi (Fig. 8B). Due to scarce material we are not able to evaluate if the observed differences in the gonocoxa habitus are of specific or of species group value.

\section{Discussion}

N. tsambagarav sp. nov. is clearly identifiable by its oligosetose $2^{\text {nd }}$ antennomere. In general the $2^{\text {nd }}$ anten- nomere of all Pseudonebriola species has a single ventral seta. According to Ledoux and Roux (2005, p. 159) $N$. stanislavi from the Kazakhstan and Russian Altai also seems to be oligosetose on the $2^{\text {nd }}$ antennomere ("deuxième article avec deux soies en dessus et une en dessous"), a statement which does not accord with the original description by Dudko and Matalin (2002). There (table p. 1082), the $2^{\text {nd }}$ antennomere is reported to be unisetose (in $66 \%$ of the cases), asymmetrically uni-/bisetose (in 21\%) and bilaterally bisetose in $11 \%$; in only 1 single specimen of 47 examined specimens (= $2 \%$ ) a third seta on the $2^{\text {nd }}$ antennomere was observed. Therefore, indication in Ledoux and Roux (2005) is incorrect. According to Dudko and Matalin (2002) the $2^{\text {nd }}$ antennomere in $N$. stanislavi is exceptionally bi- or trisetose (in 13\%), whereas in N. tsambagarav sp. nov. the $2^{\text {nd }}$ antennomere is exclusively (in $100 \%$ ) bi-, tri- or even quadrisetose. Additionally the two species differ by the bisetose sterna IV-VI and the antennal scape, which is oligosetose and distinctly longer than the eye length in $N$. stanislavi, whereas in N. tsambagarav sp. nov. the sterna IV-VI are unisetose, and the antennal scape, which is unisetose, and only as long as the eye length. Within the subgenus Pseudonebriola the oligosetose $2^{\text {nd }}$ antennomere as a non-incidental peculiarity seems to be limited to $N$. tsambagarav sp. nov.

Ledoux and Roux (2005) divided the subgenus Pseudonebriola into five species groups without specifying any main group characters. The members of the sajanica species group (N. sajanica Bänninger, 
1932, N. stanislavi, N. kaszabi) are characterized by the long antennal scape (see figures in Dudko and Matalin (2002) and Ledoux and Roux (2005)). This scape character is vaguely given by Ledoux and Roux (2005) as "long", "very long" or "about two and a half times as long as wide" in N. stanislavi, "quite long" or "two times as long as wide" in N. kaszabi. Effectively this scape slenderness seems to be more pronounced in both species. The measurement of eight specimens of $N$. kaszabi of the NMBE revealed a ratio scape length/ scape width in $N$. kaszabi of $2.47 \pm 0.06$ (2.38-2.52), a value given by Ledoux and Roux (2005) for $N$. stanislavi. Referring to the figures in Dudko and Matalin (2002; fig. 2, p. 1079) the ratio in N. stanislavi is about 2.8-3.0. Consequently, this deficient description is dissatisfying. It must be an aspect of a general revision of the subgenus Pseudonebriola (which is not the aim of the paper on hand) to clarify and to define characters on which species group arrangement is exactly based. However, the antennal scape in $N$. tsambagarav sp. nov. is distinctly shorter (ratio scape length/scape width $=2.16$ ) than in $N$. kaszabi and $N$. stanislavi of the sajanica species group, but is comparable to those of $N$. kerzhneri and $N$. medvedevi (2.16 and 1.91 respectively) of the kerzhneri species group.

The members of the sajanica species group are distributed in the Kazakhstan and Russian part of the Altai Mountain range, in the Sajan Mountains as far as to the Khamar Daban South of Baikal Lake. The members of the sajanica species group of the Kazakhstan and Russian Altai (N. sajanica, N. kaszabi, N. stanislavi) are characterized by the long antennal scape, which is bior oligosetose, and by the tarsomeres with a few dorsal setae. In contrast, the members of the kerzhneri species group (N. kerzhneri, N. medvedevi) are characterized by tarsomeres which are glabrous dorsally, and by the unisetose and short antennal scape. Due to its unisetose and short antennal scape, the dorsally glabrous tarsomeres, and due to the geographic position within the Mongolian Altai the new species $N$. tsambagarav sp. nov. is assigned to the kerzhneri species group within the subgenus Pseudonebriola.

\section{Key}

The determination key of the subgenus Pseudonebriola in Ledoux and Roux (2005) has to be modified in step 8 as follows:

8 Lateral margin of the pronotum faintly concavely sinuate in front of the posterior angles, posterior angles rectangular, not protruding outwards. $2^{\text {nd }}$ antennomere unisetose. Mongolia, Russia; main ridge of the Mongolian Altai....

N. medvedevi Shilenkov, 1982

- Lateral margin of the pronotum distinctly concavely sinuate in front of the posterior angles, posterior angles acute and

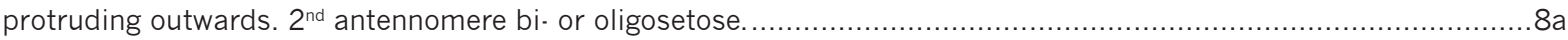

8a Colour brown. Lateral margin of the posterior angles short, slightly protruding outwards. $2^{\text {nd }}$ antennomere generally bisetose, occasionally unisetose. Elytra elliptic with lateral margin straight. Ratio antennal scape length/eye length < 0.9. Mongolia, Gobi Altai. N. kerzhneri Shilenkov, 1982

- Colour black. Lateral margin of the posterior angles long, distinctly protruding outwards. $2^{\text {nd }}$ antennomere generally tri- or quadrisetose. Elytra suboval with lateral margin rounded. Ratio antennal scape length/eye length > 0.9. Mongolia, Mongolian Altai, Tsambaragav uul. N. tsambagarav sp. nov.

\section{Acknowledgements}

The publication on hand is a result of the German-Mongolian Expedition of the Martin-Luther-University Halle, Germany (em. Prof Michael Stubbe), in collaboration with the State University Ulan-Bataar, Mongolia (Dr Lkhagvaa Lkhagvasuren). We are grateful to Dr Volker Neumann und Karl Blaue for their tireless help in fieldwork. We thank Dr Boris Kataev (ZIN), Dr Ilya Kabak and Dr I. Belousov, All-Russian Institute of Plant Protection, St Petersburg, Russia for the loan of type material of $N$. kerzhneri and N. medvedevi, and for the help with Cyrillic text. We thank Dr Thomas Burri (NMBE) for the help in designing the distribution map on QGIS, Hannes Baur (NMBE) for the help in statistics and in Keyence photographs, and Elsa Obrecht (NMBE) for her linguistic advice.

\section{References}

Baur H, Leuenberger C (2011) Analysis of Ratios in Multivariate Morphometry. Systematic Biology 60: 813-825. https://doi.org/10.1093/ sysbio/syr061

Borodavko PS, Volkova ES, Mel'nik MA, Litvinov AS, Demberel O (2018) Climate change impact on hight-altitude geomorphological systems. IOP Conference Series: Earth and Environmental Science 211: 012004. https://doi.org/10.1088/1755-1315/211/1/012004

Dudko RY, Matalin AV (2002) New and little known species of the genus Nebria (Coleoptera, Carabidae) from the Altai. Entomological Review 82(8): 1077-1083.

Gebiola M, Monti MM, Johnson RC, Wolley JB, Hunter MS, Giorgini M, Pedeta PA (2017) A revision of the Encarsia pergandiella species complex (Hymenoptera: Aphelinidae) shows cryptic diversity in parasitoids of whitefly pests. Systematic Entomology 42: 31-59. https://doi.org/10.1111/syen.12187 
Huber C (2017) Tribe Nebriini Laporte, 1834 (except genus Leistus). In: Löbl I, Löbl D (Eds) Catalogue of Palaearctic Coleoptera, Volume 2, second edition: Archostemata - Myxophaga - Adephaga. Brill Leiden-Boston, 31-60.

Huber C, Baur H (2016) Nebria (Patrobonebria) incognita n. sp. and Nebria (P.) hiekeiana n. sp., two new species from the Western Himalaya, with remarks on Nebria $(P$.) desgodinsi (Coleoptera, Carabidae, Nebriinae). Entomologische Blätter und Coleoptera 112(1): 203-214.

Huber C, Schmidt J (2018) Description of two new Nebria (Eunebria) species from Central Nepal with remarks on N. xanthacra Chaudoir, 1850 and N. cinctella Andrewes, 1925 (Insecta: Coleoptera: Carabidae: Nebriini). In: Hartmann M, Barclay M, Weipert (Eds) Biodiversität und Naturausstattung im Himalaya VI, Verein der Freunde und Förderer des Naturkundemuseums Erfurt e. V.: 283-296.

Huber C, Schmidt J, Baur H (2013) Nebria (Patrobonebria) paropamisos, a new species from the Hindu Kush (Coleoptera, Carabidae).
Contributions to Natural History 22: 1-14. https://www.e-periodica. ch/digbib/view?pid=cnh-001:2013:0\#24

Ledoux G, Roux P (2005) Nebria (Coleoptera, Nebriidae). Faune mondiale. Saint-Just-la-Pendue, Chirat, 976 pp.

Ledoux G, Roux P (2014) Une nouvelle espèce de Pseudonebriola de Chine (Coleoptera, Caraboidea, Nebriidae). Le Coléoptériste 17: 74-75.

R Core Team (2013) R: A language and environment for statistical computing. R Foundation for Statistical Computing, Vienna. http:// www.R-project.org

Shilenkov VG (1982a) A new species of the genus Nebria Latr. (Coleoptera, Carabidae) from the Altai. Folia Entomologica Hungarica. Rovartani Közlemények (S.N.) 43(1): 151-154.

Shilenkov VG (1982b) Novye i maloizvestiye zhuzhelitsy roda $\mathrm{Ne}$ bria Latr. (Coleoptera, Carabidae) iz Azii. [New and little-known ground-beetles of the genus Nebria Latr. (Coleoptera, Carabidae) from Asia.] Nasekomye Mongolii 8: 241-283. 